\title{
Early Pregnancy Human Decidua Gamma/Delta T Cells Exhibit the Tissue Resident and Specific Functional characteristics
}

\section{Shuo Yang}

Sichuan University West China Second University Hospital

\section{Ting Feng}

Sichuan University West China Second University Hospital

\section{Yong Cheng Ma}

Sichuan University West China Hospital

Hao Tie Wang

Sichuan University West China Hospital

\section{Qin Hong Chen}

Sichuan University West China Second University Hospital

\section{Man Li Li}

Sichuan University West China Second University Hospital

\section{Yuan Liu}

Sichuan University West China Second University Hospital

\section{Bin Zhou}

Sichuan University West China Second University Hospital

\section{Rong Zhou}

Sichuan University West China Second University Hospital

Hong Li ( $\square$ lihonghx@scu.edu.cn )

West China Second University Hospital, Sichuan University

\section{Research}

Keywords: Maternal-fetal interface, Decidua, $ү \delta$ T cells, Growth Factor, Immune cells

Posted Date: May 10th, 2021

DOI: https://doi.org/10.21203/rs.3.rs-476323/v1

License: (1) (1) This work is licensed under a Creative Commons Attribution 4.0 International License. Read Full License 


\section{Abstract}

Background: A successful pregnancy is a complicated process that builds upon two aspects of the maternal immune system that needs to be balanced. As one of the dominant groups of cells at the maternal fetal interface, the decidual $ү \delta T$ cells have attracted great research attention in normal pregnancy or miscarriage. However, the role of $\gamma \delta \mathrm{T}$ cells in fetal growth still remains poorly studied.

Results: In this study, we identified $ү \delta T$ cells were enriched and resident in decidua during early pregnancy, and early decidual $\gamma \delta T$ cells were involved in the secretion of growth factors, including growth differentiation factor 15 (GDF15) and bone morphogenetic protein 1 (BMP1). Decrease of these growth factors could impaire fetal development, resulting in fetal growth restriction. We also observed that the early decidual $\gamma \delta T$ cells exhibited stronger cytokine secretion characteristic, but its cytotoxicity against A549 cells was weaker, when compared with the $\gamma \delta$ T cells in peripheral blood mononuclear cells (PBMCs). In addition, the functional abilities of early decidual $\gamma \delta T$ cells in promoting trophoblast cell proliferation, migration, invasion and tube formation were also significantly stronger than those in $ү \delta \mathrm{T}$ cells of PBMCs.

Conclusions: These findings highlighted the importance of $\gamma \delta \mathrm{T}$ cells in fetal growth and maternal immune tolerance during pregnancy, which is different from $ү \delta T$ cells in PBMCs, and encouraged further research in this field.

\section{Background}

Pregnancy is a unique immunological phenomenon in which mother and the hemiallogeneic fetus peacefully coexist [1]. In order for a successful pregnancy to occur, the maternal-fetal interface plays an indispensable role in creating an environment that requires bot promotion of fetal growth and maintenance of immune tolerance [2]. The maternal-fetal interface is composed of the maternally derived decidua and the fetally derived placenta, including decidual stromal cells, decidual immune cells, and trophoblast cells $[3,4]$. During implantation, the blastocyst attaches to the decidualized endometrium and the trophectoderm of the blastocyst develops into the placenta [5]. In the process of decidualization, fetal and maternal mediated the remodeling of spiral artery, which makes the placenta bathe in the maternal blood and promotes the exchange of nutrients, gases and wastes [6]. Immune microenvironment of maternal fetal interface, including natural killer cells, macrophages and T cells, have also been reported to be involved in this remodeling process $[7,8]$. In addition, there are increasing evidences show that endometrial receptivity to semi allogeneic embryo implantation is related to maternal fetal interface immune microenvironment [9].

It is now generally considered that a successful pregnancy requires a robust, dynamic and responsive maternal immune system, which coordinated by cells of the innate and adaptive immune systems but also the decidual microenvironment [10]. Decidua is considered to be the site of immune interaction between the mother and the semi allogeneic fetus [11]. In addition, previous studies have reported that 
the decidual immune cells are different in composition, phenotype and function, and change with the stage of gestation [12]. The immune cells were recruited in human early decidua, including decidua natural killer (dNK) cells (70\%), macrophages (20\%), and T cells (5-20\%). Toward term decidua, the frequency of dNK cells decreased, while the frequency of T cells increased. The dynamic changes of immune cell composition also occurred during pregnancy in mice [13-15]. So far, NK cells are the relatively well-studied immune cells at the maternal fetal interface [16-19], while the research of $ү \delta T$ cells, another dominant cell group at the maternal fetal interface, and its role in pregnancy are far from understood and quite controversial.

y $\delta \mathrm{T}$ cells are an important subset of T lymphocytes that play important roles in innate and adaptive immunity via the secretion of various cytokines[20,21]. Different from the traditional CD $4^{+}$and $C D 8^{+} T$ cells, $\gamma \delta$ T cells express heterodimeric TCRs consist of gamma $(\gamma)$ and delta $(\delta)$ chains [22]. $\gamma \delta T$ cells represented $5-10 \%$ of $\mathrm{T}$ lymphocytes in human peripheral blood, while $\gamma \delta \mathrm{T}$ cells accounted for over $30 \%$ of T cells in human early decidua. In addition, decidua $\gamma \delta T$ also cells involved in maintenance of pregnancy by recognizing alloantigen without $\mathrm{MHC}$ restriction, producing cytokines and connecting the innate and adaptive immune responses as a bridge [23-25]. However, some authors reported that there was no change in the proportion of $ү \delta T$ cells during pregnancy [26]. Other study has observed changes of decidua $\gamma \delta T$ cell subtypes during pregnancy may associate with recurrent spontaneous abortion [27]. These studies indicated that the study of $\gamma \delta T$ cells at maternal fetal interface was still relatively superficial, and the role of $\gamma \delta T$ in early pregnancy needed to be further explored [28]. Moreover, $ү \delta T$ cells have been studied for decades as an example of specific immune cell with regulatory activity during the evolution of mammalian pregnancy [29-31]. However, whether decidua $ү \delta T$ cells participate in the early optimization of maternal nourishment of the fetus remains unknown. Here, we focus on whether early decidua $ү \delta T$ cells are responsible for maintaining the nourishing function in the early fetus. We also examine specific characteristics of decidual $\gamma \delta T$ cells, and their regulatory effects on trophoblasts to evaluate the possible functional roles of decidual $ү \delta T$ cells in the placentation and maintenance of normal pregnancy.

\section{Results}

\section{1. $y \delta T$ cells are enriched and resident in early decidua tissue at the the maternal fetal interface during human early pregnancy}

To know characteristics of distribution of decidua $ү \delta T$ at the human maternal fetal interface, immunohistochemical assay was carried out. We observed the decidual $\gamma \delta T$ cells were mainly distributed around the glands as clusters, and were scattered in the decidual stromal cells as single cells (Fig. 1A). We also identified staining intensity of $\gamma \delta \mathrm{T}$ in early decidua tissue was significantly stronger than in term decidua tissue (Fig. 1B), revealed that $\gamma \delta T$ cells were enriched in early decidua probably. So we further profiled the expression of $y \delta T$ in early decidua compared with term decidua, PBMCs of 
pregnant and PBMCs of non-pregnant through flow cytometry. We observed the proportion of $\gamma \delta \mathrm{T}$ $\left(\mathrm{CD}^{+} \mathrm{CD} 45^{+}\right)$in early decidua $(11.06 \pm 1.65 \%)$ increased significantly compared with term decidua (7.54 $\pm 0.77 \%$ ) and PBMCs of pregnant (6.13 $\pm 1.22 \%)$ (Fig. 1C, D). No difference in $\gamma \delta T$ cell numbers in PBMCs of pregnant $(6.13 \pm 1.22 \%)$ women was detected compared with Term decidua $(7.54 \pm 0.77 \%)$ and PBMCs of non-pregnant $(5.15 \pm 1.36 \%$ ) (Fig. 1C, D). Moreover, we also analyzed the main subsets of $\gamma \delta \mathrm{T}$ cells in early, term decidua and PBMCs. We identified V $\delta 1$ subset accounted for higher percentages of $\gamma \delta T$ cells in the early decidua. Conversely, the term decidua and PBMCs were dominated by the Vס2 subset (Fig. 1E, $F, G)$. These findings showed $\gamma \delta T$ cells were resident cells of decidual tissue showing specific location and were highly enriched in early decidua.

\section{The higher level of resident maker was identified in $y \delta \mathrm{T}$ cells from early deicuda.}

In order to further explore the resident characteristics of $\gamma \delta \mathrm{T}$ cells at the maternal fetal interface, human

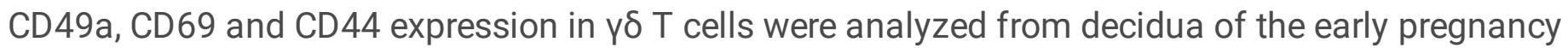
through flow cytometry compared to those from term decidua and PBMCs. We observed the higher proportion of CD 49a in $\gamma \delta \mathrm{T}$ cells from early decidua (69.26 $\pm 7.07 \%$ ) compared with term decidua (52.52 $\pm 8.53 \%)$ and PBMCs $(15.04 \pm 6.61 \%)$. The proportion of CD 49a in $\gamma \delta \mathrm{T}$ cells from term decidua was also higher than from PBMCs (Fig. 2A, B). Moreover, more than $85 \%$ of $\gamma \delta$ T cells from early decidua $(92.15 \pm$ $2.71 \%$ ) and term decidua (88.13 $\pm 8.16 \%$ ) expressed CD 69 compared with PBMCs $(6.29 \pm 3.15 \%)$ (Fig. 2A, $B)$. However, no differences in the percentage of $C D 44^{+} \gamma \delta T$ cells were found in the early decidua compared to term decidua and PBMCs (Fig. 2A, B). Our findings further showed that $\gamma \delta T$ cells from decidua have resident characteristics in maternal fetal interface.

\section{RNA-seq analysis of $\mathrm{y} \delta \mathrm{T}$ cells indicated that significant function altered in early decidual}

To explore whether $\gamma \delta T$ cells that enriched in early decidua have specific functions compared with term decidua and PBMCs, $\gamma \delta T$ cells were purified and analyzed through mRNA sequencing. There were 1573 upregulated genes and 1391 downregulated genes between the early decidual $\gamma \delta T$ cells and $\gamma \delta T$ cells of PBMCs (Fig. 3A). There also were 1670 upregulated genes and 1365 downregulated genes between the early and term decidual $\gamma \delta$ T cells (Fig. 3D). To further study the function of differentially expressed genes in early decidual $\gamma \delta T$ cells, Go analysis was performed. Go analysis revealed that these differentially expressed genes altered in early decidual $ү \delta T$ cells were mainly enriched in some biological pathways including cytokine activity, growth, growth hormone secretion, cell-cell adhesion mediator activity, growth factor activity (Fig. 3B,3E). Subsequently, we focused on 15 genes related to embryonic development and immune tolerance. Heatmap showing the different expression of selected genes in early decidual $\gamma \delta T$ cells compared with that in term decidual $\gamma \delta$ T cells and $\gamma \delta T$ of PBMCs (Fig. 3C, 3F). These results indicated that significant function altered in early decidual $ү \delta \mathrm{T}$ cells compared with term decidual 
and PBMCs. Therefore, it was meaningful to further study the roles of the $\gamma \delta \mathrm{T}$ cells during human pregnancy.

\section{Pregnancy-induced alterations in $\gamma \delta \mathrm{T}$ Cell Phenotype and Function}

To know whether $y \delta T$ cells phenotype is different during human pregnancy, we performed comparative analysis of the phenotype of $y \delta T$ cells, including NKG2D (a hallmark receptor for $y \delta$ T cells), HLA-DR (T cells activation marker), CD38 (immune cell activation maker), CD31 (platelet/endothelial cell adhesion molecule 1). We found that NKG2D, HLA-DR, CD38 and CD31 expressed at significantly higher levels in early decidual $ү \delta T$ cells than $\gamma \delta T$ cells from PBMCs (Fig. 4A). In addition, the expression of these makers in early decidual $\gamma \delta T$ cells was higher than term decidual $\gamma \delta T$ cells, except the expression of HLA-DR (Fig. 4B-4E). Furthermore, we explored the function of $\gamma \delta T$ cells in early pregnancy. We first analyzed the expression of TNF-a, IFN- $\gamma$, IL-10, IL-17a and TGF- $\beta 1$ in $\gamma \delta$ T cells via flow cytometry. TNF-a, IFN- $\gamma$ and IL-17a are pro-inflammatory cytokines that mainly mediate the cellular immune response, while IL-10 is anti-inflammatory cytokines that mediate the humoral immune response and TGF- $\beta 1$ could inhibit the differentiation of lymphocytes and the production of cytokines. Interestingly, we observed the expressed levels of TNF-a, IFN- $\gamma$, IL-10, IL-17a and TGF- $\beta 1$ in early decidual $\gamma \delta$ T cells were significantly higher than those in $\gamma \delta T$ cells from PBMCs (Fig. 4F). Moreover, the proportion of TNF- $a$, IFN- $\gamma$ and IL-17a in early decidual $y \delta T$ cells was also higher than those in term decidual $\gamma \delta T$ cells (Fig. 4G-4K). Cytotoxicity is a major function of $y \delta \mathrm{T}$ cells and also an important indicator of the functional status of $\gamma \delta T$ cells. We next explored the cytotoxicity of $\gamma \delta T$ cells against A549 cells in early decidua, term decidua and PBMCs when effector cells: target cells were 20:1. We identified the cytotoxicity of $y \delta T$ cells in early decidua was significantly lower than that in term decidua and PBMCs (Fig. 4L, M). Meanwhile, cytotoxicity of $\gamma \delta \mathrm{T}$ cells in term decidua was also lower than that in PBMCs (Fig. 4L, M). Our findings indicated that $\gamma \delta \mathrm{T}$ cells were more activated and secreted more cytokines during early pregnancy, but exhibited lower cytotoxicity.

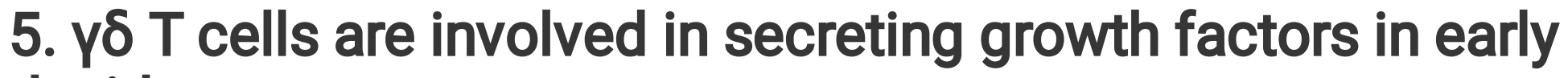 decidua.}

To validate the sequencing results, eight genes related to maternal fetal interface were selected to validate using reverse transcription polymerase chain reaction (RT-PCR), including Sprouty2(SPRY2),Kisspeptin-1(KISS1), Insulin Like Growth Factor Binding Protein 5 (IGFBP5), platelet/endothelial cell adhesion molecule 1 (CD31), Insulin Like Growth Factor Binding Protein 2 (IGFBP2), vascular endothelial growth factor C (VEGFC), growth differentiation factor 15 (GDF15), bone morphogenetic protein 1 (BMP1). The qRT-PCR results were similar to those observed in sequencing results (Fig. 5A). Meanwhile, we want to further explore the role of $y \delta T$ cells in early embryonic development, which is different from that of immune cells. To identify genes promoting fetal development in early pregnancy, gene expression was measured in sorted $\mathrm{\delta} \delta \mathrm{T}$ cells from early decidua of 
pregnancy compared with the sorted $\gamma \delta$ T cells from term decidua and PBMCs through immunofluorescence. We identified that $\gamma \delta T$ cells from early decidua upregulated several growth factors, including IGFBP2, VEGFC, GDF15 and BMP1, compared to these products in $\gamma \delta$ T cells from term decidua and PBMCs (Fig. 5B, C, D). In addition, in order to further determine that $\gamma \delta T$ cells secrete growth factors to promote embryo growth and development, growth factor genes expression was analyzed in sorted $ү \delta \mathrm{T}$ cells from patients experiencing recurrent spontaneous abortion (RSA). Contrary to the high growth factors expression in early decidua $ү \delta T$ cells, significantly decreased expression of growth factors, including IGFBP2, VEGFC, GDF15 and BMP1, were confirmed in $\gamma \delta T$ cells from RSA patients via immunofluorescence and qRT-PCR (Fig. 5E, F). These growth factors are critical for the development of blood vessels, bone, and neurite in the fetus. Therefore, insufficient secretion of growth factors in $ү \delta T$ cells from RSA patients may be responsible for the confined fetal development.

\section{Early decidual $y \delta \mathrm{T}$ cells promote the human trophoblasts migration and invasion}

Extra villous trophoblast cells (EVTs) play a critical role in maintaining sufficient maternal blood flow to support placental function and EVT invasion is an important process for fetal implantation and placenta formation $[1,4,5]$. In order to explore whether $\gamma \delta T$ cells have effects on the invasion and migration of trophoblast, we established $\gamma \delta$ T cells and HTR8/SVneo cells, a human trophoblast cell line, co-culture system using a $8 \mu \mathrm{m}$ Transwell insert. Isolated $ү \delta \mathrm{T}$ cells were placed in the lower chamber, while HTR8/SVneo cells were added the upper chamber with or without matrigel. We identified the numbers of migrated and invaded HTR8/SVneo cells increased significantly in early decidua compared with those in Control (HTR8/SVneo cells without isolated $ү \delta$ T cells), term decidua and PBMCs (Fig. 6). Meanwhile, the numbers of migrated HTR8/SVneo cells in term decidua were higher than that in PBMCs (Fig. 6B). No difference in the numbers of migrated and invaded HTR8/SVneo cells between control and PBMCs was found (Fig. 6B, D). Our observations suggested early decidual $\gamma \delta ~ T$ cells could significantly promote the migration and invasion of trophoblast cells, while that the ability of $\gamma \delta$ T cells in PBMCs to affect the migration and invasion of trophoblasts was obviously weaker.

\section{7. $y \delta$ T cells promote the human trophoblasts proliferation and tube formation during early pregnancy}

Trophoblast cells form villi through division, proliferation and differentiation, and villi are an important part of placental formation [32, 33]. To evaluate the effect of $y \delta T$ cells on the proliferation of trophoblast cells. We established isolated $\gamma \delta T$ cells and HTR8/SVneo cells directly co-culture system. Then we analyzed the proliferation ability of HTR8/SVneo cells via flow cytometry. 7-AAD ${ }^{+} \mathrm{Ki}-67^{+} \mathrm{HTR} 8 / \mathrm{SVneo}$ cells were used to represent the cohort of S/G2-M proliferating cells. After co-culture of $\gamma \delta T$ cells isolated from early decidua and trophoblast cells, we found the proportion of proliferating cells (S-G2/M) was significantly higher than those in control and the proportion of proliferating cells in term decidua was also higher than that in control (Fig. 7A, B). While the proportion of proliferating cells between PBMCs and control showed no significant differences (Fig. 7A, B). Previous studies reported that trophoblast was 
involved in the process of uterine spiral artery remodeling to form placenta $[4,9]$. To determine whether the effect of $\gamma \delta T$ cells on the tube formation of trophoblast cells, tube formation assays were performed. As shown in Figs. 7C, decreased tube formation was observed in control and PBMCs compared with early decidua. The quantitative results demonstrated that the total tube length, the total branch length, and the number of nodes in HTR8/SVneo cells from early decidua significantly increased compare with those in PBMCs (Fig. 7D). Additionally, the total tube length and the number of nodes of HTR8/SVneo cell in early decidua were also higher than those in control (Fig. 7D). Analysis of the total tube length, the total branch length, and the number of nodes in PBMCs exhibited no differences compared with control (Fig. 7D). Our results showed that $\gamma \delta T$ cells from early decidua exhibited the ability to promote trophoblast proliferation and tubule formation compared with $\gamma \delta T$ cells in PBMCs.

\section{Discussion}

Maintaining a balance in decidual immune microenvironment is essential for normal pregnancy. Previous studies showed decidual $ү \delta T$ cells were the key effector immune cells in the maternal-fetal interface in early pregnancy, which were associated with maintaining immune tolerance by producing cytokines [25, 34]. However, the role of decidual $\gamma \delta T$ cells in the maternal fetal interface is not comprehensive, some of them are even a matter of debate. In this study, we found $\gamma \delta$ T cells were enriched and resided in early decidua. We also identified early decidual $\gamma \delta T$ cells were involved in the secretion of growth factors, and the loss of these growth factors impaired fetal development, resulting in fetal growth restriction. In addition, our studies revealed early decidua $y \delta T$ cells affected the function of trophoblast, which may have effects on the development of placenta. These findings highlighted a novel and important role of $\gamma \delta$ $T$ cells in decidua tissue during pregnancy, a function independent of its antiviral and anti-infective role.

It has been reported that the percentage of $\gamma \delta T$ cells increased during early pregnancy [34, 35].

Consistent with this, we found the percentage of $\gamma \delta T$ cells increased in early decidua compared with term deicua and PBMCs via immunohistochemical assay and flow cytometry. We and others have not found any significant fluctuation in number of $\gamma \delta T$ cells in the blood between pregnant and non-pregnant women. We also identified decidua $ү \delta T$ cells mainly localized and distributed around the decidua glands, which provide growth factors, cytokines and T-cell immunosuppressive factors, as well as nutrients in the intervillous space during early pregnancy [36-38]. Therefore, we speculate that $\gamma \delta T$ cells are a group of tissue resident cells in maternal fetal interface, and the expression of resident maker CD69 and CD49a in the decidua verifies our conjecture. In accordance with previous reports, we confirmed the majority of the human early decidual $\gamma \delta T$ cells were $V \delta 1$, while most of term decidua and PBMCs expressed V $\delta 2[35,39$, 40]. This result is consistent with the previous work which has described that immune tolerance dominates in the early decidua and gradually revises in the term decidua [41]. The main differences in $ү \delta$ $T$ cell subsets and the inverse pattern of distribution among early decidua, term decidua and PBMCs may reflect their different immunoregulation functions in both compartments.

The percentage of $\mathrm{\delta} \delta$ T cells increased in the decidua during the first trimester of pregnancy but significantly declined after the placenta is formed $[25,29]$. We investigated whether these transient $ү \delta T$ cells had specific function during the early pregnancy. NGS and bioinformatic analysis were performed to 
figure out the differentially expressed mRNA in purified $\gamma \delta T$ cells. It has been reported that decidua NK cells secreted growth factors to promote the growth and development of early embryos [18]. We also focused on whether $\gamma \delta T$ cells are involved in the secretion of growth factors to promote fetal growth and development. The data presented here showed that early decidua $\gamma \delta T$ cells have specific functions involved in secretion of growth factors, such as GDF15 and BMP1, and promoting fetal growth in human. GDF15, a member of the TGF-beta superfamily, has been shown to be implicated in many biological processes such as energy homeostasis and body weight regulation and has key roles in heart development [42, 43]. BMP1 is an astacin metalloprotease, which has key roles in the development and regeneration of bone and cartilage [44-46]. Both growth factors are critical for fetal development.

We also found that the expression levels of T cell activated receptor, NKG2D and HLA-DR, on $\gamma \delta$ T cells in early decidua were higher than that in term decidua and PBMCs. These data demonstrated that the activity of early decidua $\gamma \delta T$ cells was higher in the maternal-fetal interface. Moreover, high expression of CD31, an endothelial cell adhesion molecule [47], was also detected in early decidua, which may be related to $\gamma \delta T$ cells resident in early decidua. It is an indisputable fact that cytokines in the maternal fetal interface play an important role in the establishment and maintenance of normal pregnancy. Inconsistent with the previous report $[25,34,48]$, we identified that both pro-inflammatory and anti-inflammatory cytokines are highly expressed in early decidua, we speculated that the function of secreting cytokines by decidual $ү \delta T$ cells in early pregnancy might be stronger. Cytotoxicity is an important functional indicator of $y \delta T$ cells that arising from an abnormal balance between inhibitory and activating signaling [49].We demonstrated that early decidua $\gamma \delta T$ cells exhibited lower cytotoxicity against A549 cells, this might suggest that decidua $\gamma \delta T$ cells at the maternal-fetal interface are relatively immunosuppressive during early pregnancy and might also be a sign of enhanced tolerance of early decidua $\gamma \delta \mathrm{T}$ cells.

Trophoblast cells, as the key cells in placenta, play an important role in the growth and development of fetus [1]. Trophoblast proliferation, migration and invasion are the basis of placental formation, which occurred through a series of intercellular signal transduction processes mediated by cytokines and hormones $[50,51]$. At the top of anchored villi, these cytotrophoblasts proliferate and differentiate into extravillous trophoblast (EVT). Invasive EVT plays a positive role in the remodeling of uterine spiral artery. Therefore, insufficient proliferation, migration and invasion of trophoblast can lead to poor placental formation and affect fetal development, which is directly associated with the serious complications of human pregnancy, including preeclampsia and intrauterine growth restriction [52, 53]. In this study, we investigated whether $\gamma \delta T$ cells affected placental trophoblast cells at the maternal-fetal interface during pregnancy. We identified early decidua $\gamma \delta T$ cells could enhance the proliferation, migration and invasion of trophoblast cell line HTR8 / svneo compared with those in term decidua and PBMCs. Furthermore, Angiogenesis is a key step in the development of placenta and fetus. Insufficient angiogenesis may lead to early abortion $[33,54]$. The data presented here showed that early decidua $\gamma \delta T$ cells significantly promoted tube formation in HTR8/SVneo cells. These results revealed that early decidual $\gamma \delta \mathrm{T}$ cells participated in and promoted the function of trophoblast, but this function is weaker in term decidual $ү \delta \mathrm{T}$ cells and $\gamma \delta T$ cells of PBMCs. 
Although our current results clarify the characteristics of decidual $\gamma \delta$ T cells, and decidual $\gamma \delta$ T cells present a new role in early fetal development, our research still have some limitations that need to be considered. We found that early decidual $\gamma \delta T$ cells are involved in the secretion of growth factors in early pregnancy, but the related mechanism needs to be further studied. In addition, due to the obvious species differences of $ү \delta T$ cells, we chose clinical samples for indirect verification instead of in vivo experiments. Although HTR8 / svneo cells have been shown to effectively reproduce key aspects of EVTs [55], the validity of using immortalized cell lines to represent the in vivo environment remains questionable [56].It is necessary to isolate and acquire primary trophoblast cells and conduct appropriate animal experiments. The mechanism of how decidua $y \delta \mathrm{T}$ cells affect the function of trophoblast also require to further explore in order to provide stronger evidence for our current research in the following work.

\section{Conclusions}

In summary, we have provided evidence that $\gamma \delta T$ cells are enriched and resident in decidua during early pregnancy, and early decidual $\gamma \delta \mathrm{T}$ cells were involved in the secretion of growth factors. Moreover, Decrease of these growth factors could impaire fetal development, resulting in fetal growth restriction. These findings highlighted a novel and important role of $ү \delta T$ cells in decidua tissue during pregnancy, a function independent of its antiviral and anti-infective role.

\section{Material And Methods}

\section{Study Population and Samples}

Healthy pregnant women in early pregnancy, directed to elective pregnancy termination (6-12 weeks, $\mathrm{n}=$ 41) and in term pregnancy, directed to cesarean section (37-40 weeks, $n=30)$ were involved in the study. 10 deciduas from abnormal pregnancies were obtained from patients who experienced recurrent spontaneous abortions. Women with endocrine and metabolic diseases (diabetes, hyperthyroidism, and hypothyroidism), hypertension, or infectious diseases (hepatitis, AIDS, syphilis, or any other bacterial or viral infection) were excluded. Written informed consent was taken from all subjects for the use of blood and tissue samples. The research protocol was approved by the Ethics Committee of West China Second University Hospital of Sichuan University and informed consent was obtained from all participants [Approval number: Medical research 2020 (029)]. All samples were collected under sterile conditions.

\section{The Isolation of Decidual Immunocytes and Peripheral Blood Mononuclear Cells}

Decidual sample isolation was performed according to previous report [34]. Briefly, fresh decidua samples were washed and minced into small pieces. Decidual tissues were released by digesting the tissues with $1 \mathrm{mg} / \mathrm{mL}$ collagenase type IV (Sigma, USA) and $150 \mathrm{U} / \mathrm{mL}$ of DNase I (Applichem, Germany) in RPMI 1640 medium for 1 hour at $37^{\circ} \mathrm{C}$. The suspensions were strained through nylon mesh and then loaded onto a percoll density gradient $(60 \%, 40 \%, 20 \%)$ to purify the lymphocytes. Blood samples were obtained 
in heparin anti-coagulated vacutainer tubes (BD Biosciences, USA). Peripheral blood mononuclear cells were isolated according to previous report [35]. The DICs and PBMCs were re-suspended in RPMI1640 supplemented with $10 \% \mathrm{FBS}, 1 \%$ penicillin and streptomycin, and cultured at $37^{\circ} \mathrm{C}, 5 \% \mathrm{CO} 2$.

\section{Human $ү \delta \mathrm{T}$ cells isolation}

үठ T cells were separated from decidua and PBMCs by positively selection using a magnetic isolation kit (Miltenyi Biotec, Germany) according to the manufacturer instructions. The purity of the enriched $\gamma \delta \mathrm{T}$ cells was evaluated by flow cytometry (Becton Dickinson, USA). The purity of the isolated cells exceeded $90 \%$.

\section{Immunohistochemistry and Immunofluorescence}

Decidual tissues immunohistochemistry staining was treated as previously described [35]. Briefly, Early and term pregnancy decidual tissues $(10 \mathrm{~mm} * 10 \mathrm{~mm} \star 10 \mathrm{~mm}$ ) were fixed in $4 \%$ PFA (Biosharp) overnight. Primary mouse anti-human TCR mAb (5A6.E9, Thermo Fisher Scientific) (1:100) diluted in 1\% bovine serum albumin/PBS was added for overnight incubation at $4^{\circ} \mathrm{C}$ in a humidified chamber. The peroxidase activity was revealed with ready-to-use 3,3-diaminobenzidine tetrahydrochloride (DAB). Nuclei were slightly counterstained with hematoxylin.

үठ T cells from either PBMCs or deciduas were purified using MACS ( $\gamma \delta$ T Cell Isolation Kit, human; Miltenyi Biotec). The purified cells were fixed with $4 \%$ PFA and incubated in blocking buffer ( $5 \%$ normal goat serum, $0.5 \%$ Triton X-100 in PBS) at room temperature for $30 \mathrm{~min}$. Primary antibodies was added and incubated overnight at $4{ }^{\circ} \mathrm{C}$. Then the secondary antibodies were incubated for 2 hours, followed by staining with DAPI for $10 \mathrm{~min}$. The following primary antibodies were used: mouse anti-human TCR mAb (1:100, Thermo Fisher Scientific, 5A6.E9), Rabbit anti-human BMP1 (1:100, Thermo Fisher Scientific, PA582506), Rabbit anti-human GDF15 (1:100, Abcam, ab206414), Rabbit anti-human IGFBP2 (1:100, Affinity, DF7765), Rabbit anti-human VEGFC (1:100, Affinity, DF7011). The following secondary antibodies were used: Alexa Fluor® 488-Anti-Rabbit (1:200, Jackson lab, 711-545-152), Cy3-Anti-mouse (1:200, Jackson lab, 711-165-150). All immunofluorescence staining was performed in the dark.

\section{Flow Cytometry}

For flow cytometric analysis, FACS staining was performed according to the manufacturer's instructions (BD Biosciences). Suspensions of lymphocytes were stained for the following human monoclonal antibodies: Percp/cy5.5-anti-CD3, APC-cy7-anti-CD45, PE-anti-TCRyס, FITC-anti-CD69, Alexa-Fluor 647anti-CD49a, BV421-anti-CD44, BV605-anti-NKG2D, BV650-anti-CD38 and APC-anti-CD31(all from BioLegend, USA), FITC-anti-HLA-DR and BV421-anti-TCR V82((both from B\&D, USA) and FITC-anti-TCR Vס1 (Invitrogen, USA). For the intracellular staining, isolated cells were incubated with $4 \mathrm{~h}$ of stimulation with phorbol myristate acetate (PMA; Sigma, USA) and ionomycin (Sigma, USA) in the presence of monensin (BioLegend, USA) and brefeldin A (BioLegend, USA). The antibodies used for intracellular staining respectively are APC-anti-TNF-a, FITC-anti-IFN- $\gamma$, BV605-anti-IL17a, BV421-anti-IL10, FITC-antiTGF- $\beta$ (all from BioLegend, USA). 
For $\gamma \delta T$ cell cytotoxicity analysis, a commercial LIVE/DEADTM Cell-Mediated Cytotoxicity Kit (Invitrogen, USA) was used to quantify dead cells. Briefly, $1 * 10^{6}$ cells of target cells (A549 cells, a human lung adenocarcinoma cells line) were incubated with $10 \mathrm{~mL} \mathrm{DiOC}$ for 20 minutes at $37^{\circ} \mathrm{C}$. Then the effector cells $(Y \delta T)$ and target cells were mixed at a ratio of 20:1(E:T $=20: 1)$ for 2 hours at $37^{\circ} \mathrm{C}$. Dead A549 cells $\left(\mathrm{DIOC}^{+} \mathrm{Pl}^{+}\right)$were represented as cytotoxic signal in the upper right hand quadrant.

\section{RNA Isolation and qRT-PCR}

RNA was extracted using Trizol RNA Isolation Reagents (Invitrogen, USA) according to the manufacturer's instructions. Reverse transcription was conducted with RevertAid First Strand cDNA Synthesis Kit (Thermo Fisher Scientific, USA) according to the manufacturer's instructions. qRT-PCR was performed using SYBR Green Master Mix (Thermo Fisher Scientific) on an Applied Biosystems 7500 (Life technologies, USA). GAPDH was used as an internal control. Primers were shown in Table 1.

\section{RNA-Seq}

Total RNA was isolated by Trizol RNA Isolation Reagents (Invitrogen, USA) according to the manufacturer's protocol. Purified $\gamma \delta T$ cells were used for the RNA-sEq. A total of $3 \mu \mathrm{g}$ RNA of each sample was used to prepare libraries. RNA sequencing was performed using HiSeq 4000 (Illumina, San Diego, USA) by Novogene.

\section{Transwell Invasion and Migration Assays}

The invasive and migratory ability of HTR8/SVneo cells were evaluated using the Transwell assay as previously described [48]. Briefly, Cell invasion was examined in 24-well Transwell chambers $(8 \mu \mathrm{m}$, Corning, USA). Each insert was coated with $50 \mathrm{~mL}$ Matrigel (Corning, USA) before the assay had been conducted. $5 * 10^{4}$ HTR8/SVneo cells, resuspended in $200 \mathrm{~mL}$ RMPI1640, were seeded in the upper chamber. While the same number of isolated $\gamma \delta \mathrm{T}$ cells, in $500 \mathrm{ml}$ complete medium (with 10\% FBS), were added to the bottom well. After $24 \mathrm{~h}$ incubation, the cells were fixed and stained with crystal violet. The number of stained cells was determined by light microscopy. All experiments were performed in duplicates, and the invasion index was expressed as the proportion (\%) of invaded cells compared with the corresponding control (cultured HTR8/SVneo without $\gamma \delta T$ cells). The transwell migration assay was the same as for the invasion assay, except without Matrigel.

\section{Proliferation and Tube Formation Assays}

For proliferation Assays, $1 * 10^{5} \mathrm{HTR} 8 /$ SVneo cells were cultured with RPMI 1640 complete medium (with $10 \%$ FBS) in a 24-well plate for adherent culture. Thereafter, $1 * 105$ isolated $\gamma \delta$ T cells were directly cocultured with HTR8/SVneo cells for $24 \mathrm{~h}$. Then, the cells were washed twice, collected, fixed, permeabilized, and stained with 7-AAD and Ki-67 for flow cytometry analysis. The proliferation rate was expressed as the proportion (\%) of 7-AAD $\mathrm{Ki}^{-67^{+}} \mathrm{S} / \mathrm{G} 2-\mathrm{M}$ cells.

For Tube Formation Assays, HTR8/SVneo cells were cultured with RPMI 1640 supplemented with 10\% FBS attach to the bottom of the 24-well plate. Afterward, isolated $\gamma \delta$ T cells were seeded in the $0.4 \mu \mathrm{m}$ 
upper chamber and co-cultured with HTR8/SVneo cells which were seeded in the lower chamber for $24 \mathrm{~h}$. Matrigel (Corning, USA) was placed in a 96-well cell culture plate $(60 \mu \mathrm{L} /$ well) and incubated for $30 \mathrm{~min}$ promote solidification. Then, HTR8/SVneo cells were harvested and seeded onto Matrigel-coated wells and cultured for $4 \mathrm{~h}$ until tube formation was observed. Tube formation was observed under an inverted microscope (Olympus, Japan). We quantified the number of nodes, the total branch length, and the total tube length; these data were analyzed by Image J.

\section{Statistical Analysis}

Data are given as means \pm standard deviation (SD) or median according to normality test. Statistical analysis was carried out using unpaired t-tests or non-parametric tests. The value $p<0.05$ was considered as statistically significant. All statistical analyses were performed using GraphPad Prism version 7.0c (GraphPad Software, USA).

\section{Abbreviations}

GDF15: growth differentiation factor 15; BMP1: bone morphogenetic protein 1; PBMCs: Peripheral blood mononuclear cells; TCR: T cell receptor; dNK: Decidual NK cell; TNF-a: tumor necrosis factor-a; IFN- $\gamma$ : Interferon- $;$; IL-10: Interleukin 10; TGF- $\beta$ : Transforming growth factor $\beta$; IGFBP2: insulin-like growth factor binding protein 2; IL-17a: interleukin-17a; VEGFC: vascular endothelial growth factor C. RSA: recurrent spontaneous abortion; EVTs: Extra villous trophoblast cells.

\section{Declarations}

\section{Ethics approval and consent to participate}

The studies involving human participants were reviewed and approved by Medical Ethics Committee of West China Second Hospital of Sichuan University. The patients or volunteers provided their written informed consent to participate in this study.

\section{Consent for publication}

Not applicable.

\section{Availability of data and materials}

The data that support the findings of this study are available from the corresponding author upon request.

\section{Competing interests}

The authors declare that they have no competing interests.

\section{Funding}


This research was supported by the National Natural Science Foundation of China (No.81971461 and No.81671497) and the Projects of Sichuan Science and Technology Department (2019YJ0066 and 2020ZYD007).

\section{Authors' Contributions}

HL and SY designed the research. SY, HQC, MLL, YL and RZ helped collect the tissues and blood samples. SY and TF performed the flow cytometry. SY, THW, BZ and CYM analyzed the sequencing results. SY and TF designed and performed most of the functional experiments. SY contributed to data analysis and wrote the manuscript. HL and RZ critically revised the manuscript. All authors read and approved the final version of the manuscript.

\section{Acknowledgments}

We would like to thank outpatient operating room and obstetrics department of West China Second University Hospital for the clinical samples.

\section{References}

1. PrabhuDas M, Bonney E, Caron K, Dey S, Erlebacher A, Fazleabas A, et al. Immune mechanisms at the maternal-fetal interface: perspectives and challenges. NAT IMMUNOL. 2015;16:328-34.

2. Schumacher A, Sharkey DJ, Robertson SA, Zenclussen AC. Immune Cells at the Fetomaternal Interface: How the Microenvironment Modulates Immune Cells To Foster Fetal Development. J IMMUNOL. 2018;201:325-34.

3. Parker EL, Silverstein RB, Verma S, Mysorekar IU. Viral-Immune Cell Interactions at the Maternal-Fetal Interface in Human Pregnancy. FRONT IMMUNOL. 2020;11:522047.

4. Pijnenborg R, Vercruysse L. M. Hanssens. The uterine spiral arteries in human pregnancy: facts and controversies. PLACENTA. 2006;27:939-58.

5. Ander SE, Diamond MS, Coyne CB. Immune responses at the maternal-fetal interface. Sci Immunol. $2019 ; 4$.

6. Moffett A, Chazara O, Colucci F. Maternal allo-recognition of the fetus. FERTIL STERIL. 2017; 107:1269-72.

7. Le Bouteiller P, Bensussan A. Up-and-down immunity of pregnancy in humans. F1000Res. 2017;6:1216.

8. Rowe JH, Ertelt JM, Xin L, Way SS. Regulatory T cells and the immune pathogenesis of prenatal infection. REPRODUCTION. 2013;146:R191-203.

9. Yang F, Zheng Q, Jin L. Dynamic Function and Composition Changes of Immune Cells During Normal and Pathological Pregnancy at the Maternal-Fetal Interface. FRONT IMMUNOL. 2019;10:2317.

10. Hsu P, Nanan RK. Innate and adaptive immune interactions at the fetal-maternal interface in healthy human pregnancy and pre-eclampsia. FRONT IMMUNOL. 2014;5:125. 
11. Solders M, Gorchs L, Gidlof S, Tiblad E, Lundell AC. H. Kaipe. Maternal Adaptive Immune Cells in Decidua Parietalis Display a More Activated and Coinhibitory Phenotype Compared to Decidua Basalis. STEM CELLS INT. 2017;2017:8010961.

12. Williams PJ, Searle RF, Robson SC, Innes BA, Bulmer JN. Decidual leucocyte populations in early to late gestation normal human pregnancy. J REPROD IMMUNOL. 2009;82:24-31.

13. Faas MM, de Vos P. Uterine NK cells and macrophages in pregnancy. PLACENTA. 2017;56:44-52.

14. Bulmer JN, Williams PJ, Lash GE. Immune cells in the placental bed. INT J DEV BIOL. 2010;54:28194.

15. Whitelaw PF, Croy BA. Granulated lymphocytes of pregnancy. PLACENTA. 1996;17:533-43.

16. Manaster I, Mandelboim 0 . The unique properties of uterine NK cells. AM J REPROD IMMUNOL. 2010;63:434-44.

17. Carlino C, Stabile H, Morrone S, Bulla R, Soriani A, Agostinis C, et al. Recruitment of circulating NK cells through decidual tissues: a possible mechanism controlling NK cell accumulation in the uterus during early pregnancy. BLOOD. 2008;111:3108-15.

18. Fu B, Zhou Y, Ni X, Tong X, Xu X, Dong Z, et al. Natural Killer Cells Promote Fetal Development through the Secretion of Growth-Promoting Factors. IMMUNITY. 2017;47:1100-13.

19. Co EC, Gormley M, Kapidzic M, Rosen DB, Scott MA, Stolp HA, et al. Maternal decidual macrophages inhibit NK cell killing of invasive cytotrophoblasts during human pregnancy. BIOL REPROD. 2013;88:155.

20. Cavalcanti DAR, Granato A, Silva Cl, Carvalho TR, Santos SF, Lima MA, et al. Phenotypic and functional changes in gamma delta T lymphocytes from HTLV-1 carriers. J Leukoc Biol. 2019;106:607-18.

21. A.C. Hayday. gammadelta T Cell Update: Adaptate Orchestrators of Immune Surveillance. J IMMUNOL. 2019;203:311-20.

22. Hayday AC. Gammadelta T cells and the lymphoid stress-surveillance response. IMMUNITY. 2009;31:184-96.

23. Szekeres-Bartho J, Barakonyi A, Miko E, Polgar B, Palkovics T. The role of gamma/delta T cells in the feto-maternal relationship. SEMIN IMMUNOL. 2001;13:229-33.

24. Poggi A. M.R. Zocchi. gammadelta T Lymphocytes as a First Line of Immune Defense: Old and New Ways of Antigen Recognition and Implications for Cancer Immunotherapy. FRONT IMMUNOL. 2014;5:575.

25. Chang RQ, Shao J, Meng YH, Wang J, Li DJ, Li MQ. Decidual RANKL/RANK interaction promotes the residence and polarization of TGF-beta1-producing regulatory gammadelta T cells. CELL DEATH DIS. 2019;10:113.

26. Vassiliadou N, Bulmer JN. Quantitative analysis of T lymphocyte subsets in pregnant and nonpregnant human endometrium. BIOL REPROD. 1996;55:1017-22. 
27. Cai $D$, Tang $Y$, Yao X. Changes of gammadeltaT cell subtypes during pregnancy and their influences in spontaneous abortion. J REPROD IMMUNOL. 2019;131:57-62.

28. Huang C, Zeng Y, Tu W. The role of gammadelta-T cells during human pregnancy. AM J REPROD IMMUNOL. 2017;78.

29. Polgar B, Barakonyi A, Xynos I, Szekeres-Bartho J. The role of gamma/delta T cell receptor positive cells in pregnancy. AM J REPROD IMMUNOL. 1999;41:239-44.

30. Holtmeier W. D. Kabelitz. gammadelta T cells link innate and adaptive immune responses. Chem Immunol Allergy. 2005;86:151-83.

31. Kobayashi H. Y. Tanaka. gammadelta T Cell Immunotherapy-A Review. Pharmaceuticals (Basel). 2015;8:40-61.

32. Tessier DR, Yockell-Lelievre J. A. Gruslin. Uterine Spiral Artery Remodeling: The Role of Uterine Natural Killer Cells and Extravillous Trophoblasts in Normal and High-Risk Human Pregnancies. AM J REPROD IMMUNOL. 2015;74:1-11.

33. Xueya Z, Yamei L, Sha C, Dan C, Hong S, Xingyu Y, et al. Exosomal encapsulation of miR-125a-5p inhibited trophoblast cell migration and proliferation by regulating the expression of VEGFA in preeclampsia. Biochem Biophys Res Commun. 2020;525:646-53.

34. Fan DX, Duan J, Li MQ, Xu B, Li DJ, Jin LP. The decidual gamma-delta T cells up-regulate the biological functions of trophoblasts via IL-10 secretion in early human pregnancy. CLIN IMMUNOL. 2011;141:284-92.

35. Terzieva A, Dimitrova V, Djerov L, Dimitrova P, Zapryanova S, Hristova I, et al. Early Pregnancy Human Decidua is Enriched with Activated, Fully Differentiated and Pro-Inflammatory Gamma/Delta T Cells with Diverse TCR Repertoires. INT J MOL SCl. 2019;20.

36. Rachmilewitz J, Riely GJ, Tykocinski ML. Placental protein 14 functions as a direct T-cell inhibitor. CELL IMMUNOL. 1999;191:26-33.

37. Hempstock J, Cindrova-Davies T, Jauniaux E, Burton GJ. Endometrial glands as a source of nutrients, growth factors and cytokines during the first trimester of human pregnancy: a morphological and immunohistochemical study. Reprod Biol Endocrinol. 2004;2:58.

38. Carson DD, Bagchi I, Dey SK, Enders AC, Fazleabas AT, Lessey BA, et al. Embryo implantation. DEV BIOL. 2000;223:217-37.

39. Christmas SE, Brew R, Deniz G, Taylor JJ. T-cell receptor heterogeneity of gamma delta T-cell clones from human female reproductive tissues. IMMUNOLOGY. 1993;78:436-43.

40. Mincheva-Nilsson L, Kling M, Hammarstrom S, Nagaeva O, Sundqvist KG, Hammarstrom ML, et al. Gamma delta T cells of human early pregnancy decidua: evidence for local proliferation, phenotypic heterogeneity, and extrathymic differentiation. J IMMUNOL. 1997;159:3266-77.

41. Shah NM, Herasimtschuk AA, Boasso A, Benlahrech A, Fuchs D, Imami N, et al. Changes in T Cell and Dendritic Cell Phenotype from Mid to Late Pregnancy Are Indicative of a Shift from Immune Tolerance to Immune Activation. FRONT IMMUNOL. 2017;8:1138. 
42. Baek SJ, Eling T. Growth differentiation factor 15 (GDF15): A survival protein with therapeutic potential in metabolic diseases. Pharmacol Ther. 2019;198:46-58.

43. Wang T, Liu J, McDonald C, Lupino K, Zhai X, Wilkins BJ, et al. GDF15 is a heart-derived hormone that regulates body growth. EMBO MOL MED. 2017;9:1150-64.

44. Ge G, Greenspan DS. Developmental roles of the BMP1/TLD metalloproteinases. Birth Defects Res C Embryo Today. 2006;78:47-68.

45. Kessler E, Takahara K, Biniaminov L, Brusel M. D.S. Greenspan. Bone morphogenetic protein-1: the type I procollagen C-proteinase. SCIENCE. 1996;271:360-2.

46. Asharani PV, Keupp K, Semler O, Wang W, Li Y, Thiele H, et al. Attenuated BMP1 function compromises osteogenesis, leading to bone fragility in humans and zebrafish. AM J HUM GENET. 2012;90:661-74.

47. Merchand-Reyes G, Robledo-Avila FH, Buteyn NJ, Gautam S, Santhanam R, Fatehchand K, et al. CD31 Acts as a Checkpoint Molecule and Is Modulated by FcgammaR-Mediated Signaling in Monocytes. J IMMUNOL. 2019;203:3216-24.

48. Lin F, Yang C, Feng T, Yang S, Zhou R, Li H. The Maternal-Fetal Interface in Small-for-Gestational-Age Pregnancies Is Associated With a Reduced Quantity of Human Decidual NK Cells With Weaker Functional Ability. Front Cell Dev Biol. 2020;8:633.

49. Deroost K. J. Langhorne. Gamma/Delta T Cells and Their Role in Protection Against Malaria. FRONT IMMUNOL. 2018;9:2973.

50. Norwitz ER, Schust DJ, Fisher SJ. Implantation and the survival of early pregnancy. N Engl J Med. 2001;345:1400-8.

51. Mellor AL, Munn DH. Immunology at the maternal-fetal interface: lessons for T cell tolerance and suppression. ANNU REV IMMUNOL. 2000;18:367-91.

52. Ridder A, Giorgione V, Khalil A, Thilaganathan B. Preeclampsia: The Relationship between Uterine Artery Blood Flow and Trophoblast Function. INT J MOL SCl. 2019;20.

53. Duttaroy AK, Basak S. Maternal dietary fatty acids and their roles in human placental development. Prostaglandins Leukot Essent Fatty Acids. 2020;155:102080.

54. Zhi Z, Yang W, Liu L, Jiang X, Pang L. Early missed abortion is associated with villous angiogenesis via the HIF-1alpha/VEGF signaling pathway. ARCH GYNECOL OBSTET. 2018;298:537-43.

55. Wang S, Qian J, Sun F, Li M, Ye J, Li M, et al. Bidirectional regulation between 1st trimester HTR8/SVneo trophoblast cells and in vitro differentiated Th17/Treg cells suggest a fetal-maternal regulatory loop in human pregnancy. AM J REPROD IMMUNOL. 2019;81:e13106.

56. Orendi K, Kivity V, Sammar M, Grimpel Y, Gonen R, Meiri H, et al. Placental and trophoblastic in vitro models to study preventive and therapeutic agents for preeclampsia. PLACENTA. 2011;32(Suppl):49-54.

\section{Tables}


Table 1 Real time-PCR primers

\begin{tabular}{lc}
\hline \multicolumn{1}{c}{ Primer } & Sequence \\
\hline GAPDH-forward & GCACCGTCAAGGCTGAGAAC \\
GAPDH-reverse & TGGTGAAGACGCCAGTGGA \\
SPRY2-forward & TTGCTCGGAAGTTGGTCTAA \\
SPRY2-reverse & TCAGGTCTTGGAAGTGTGGT \\
IGFBP2-forward & AGCCCAAGAAGCTGCGACCAC \\
IGFBP2-reverse & CTGCCCGTTCAGAGACATCTTGC \\
GDF15-forward & GAGCTGGGAAGATTCGAACA \\
GDF15-reverse & AGAGATACGCAGGTGCAGGT \\
BMP1-forward & GCCACATTCAATCGCCCAA \\
BMP1-reverse & TGGCGCTCAATCTCAAAGGAC \\
IGFBP5-forward & GTCCAAGTTTGTCGGGGGAG \\
IGFBP5-reverse & AAGTCCCCGTCAACGTACTC \\
KISS1-forward & ACCTGCCTCTTCTCACCAAG \\
KISS1-reverse & TAGCAGCTGGCTTCCTCTC \\
VEGFC-forward & TGTACAAGTGTCAGCTAAGG \\
VEGFC-reverse & CCACATCTATACACACCTCC \\
CD31-forward & CAACGAGAAAATGTCAGA \\
CD31-reverse & GGAGCCTTCCGTTCTAGAGT \\
\hline
\end{tabular}

Figures 


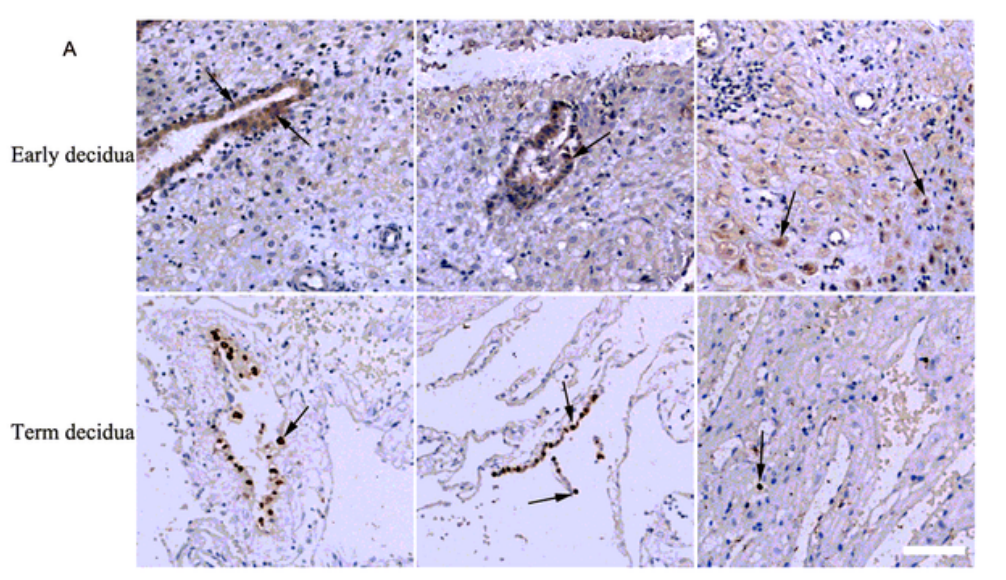

B

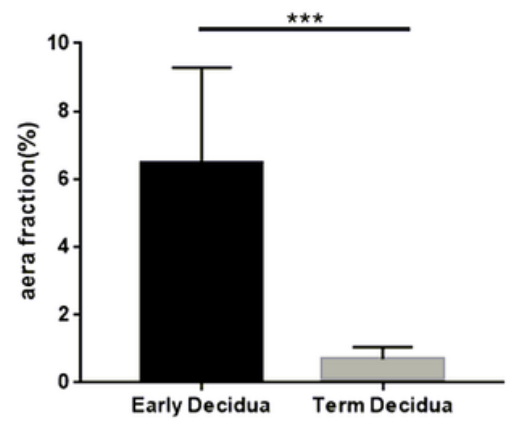

c
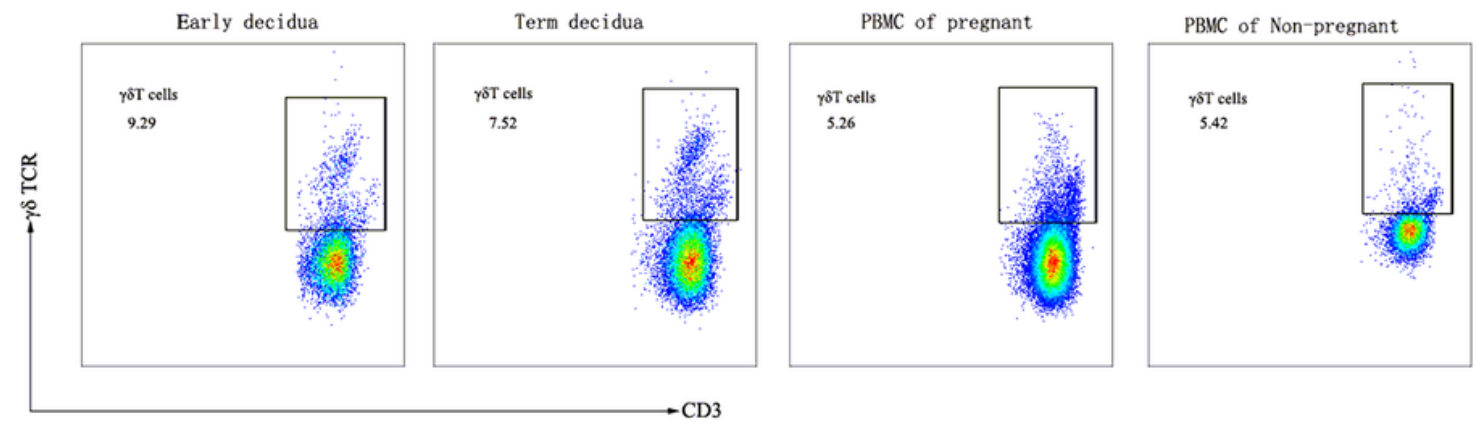

D
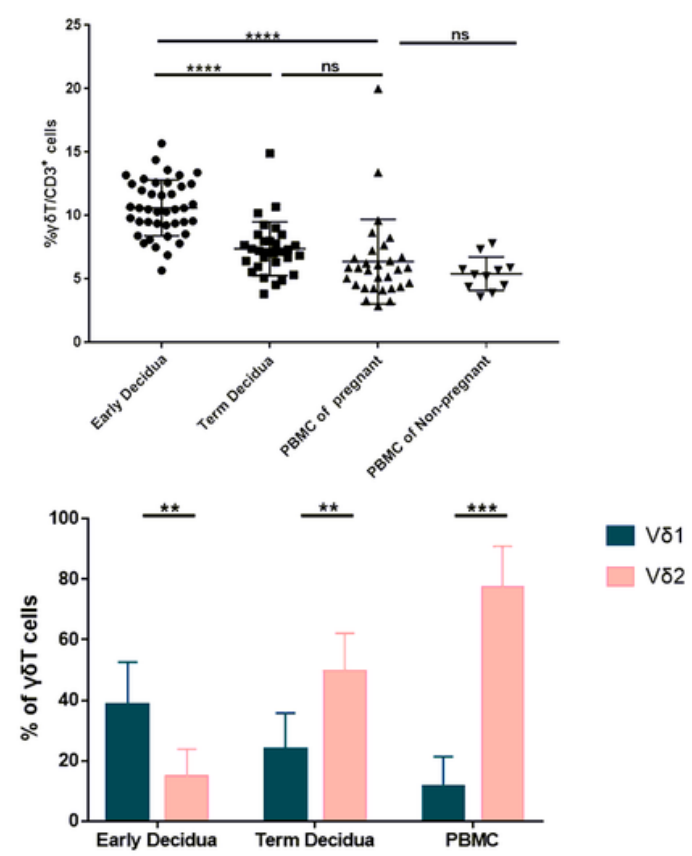

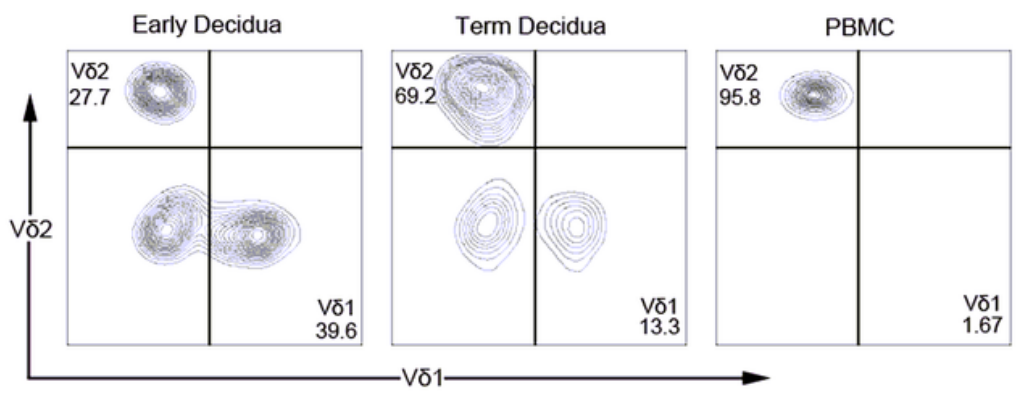

G
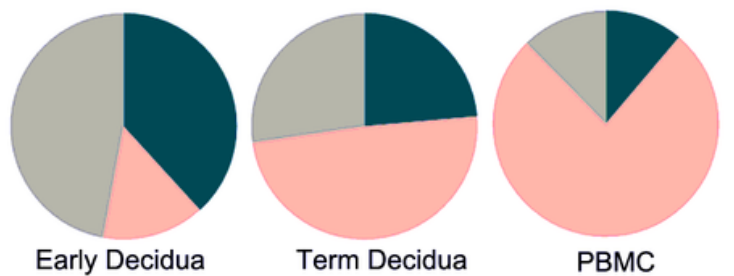

= v81

$=$ other typle of $\mathrm{Y} \delta \mathrm{T}$

PBMC

\section{Figure 1}

Distribution and phenotypes of decidua $ү \delta T$ cells at the maternal-fetal interface. (A) The distribution of of decidua $ү \delta T$ cells (arrows) at early and term decidua, as shown by immumohistochemical staining. Scale bars, $50 \mu \mathrm{m}$. $\mathrm{n}=5$ both for early and term decidua. (B) Statistical analysis of decidua $\gamma \delta \mathrm{T}$ cells immumohistochemical staining in early and term decidua. Area fraction was calculated by Image J. (C) Representative FACS plots showing the number of $\mathrm{\gamma} \delta \mathrm{T}$ cells derived from early and term decidua and PBMCs of pregnant and PBMCs of non-pregnant. The number on the top right corner of each plot denotes 
the percentage of $\gamma \delta T$ cells among CD3+ T cells (D) Summary data showing percentage of $\gamma \delta T$ cells from early decidua $(n=41)$, term decidua $(n=30)$, PBMCs of pregnant $(n=30)$ and PBMCs of non-pregnant $(n=11)$. (E) Representative figures of $V \delta 1$ and $V \delta 2$ subsets out of $\gamma \delta T$ cells from early and term decidua and PBMCs of pregnant. $(F, G)$ Quantification displaying frequencies of $V \delta 1$ and $V \delta 2$ subsets out of $y \delta T$ cells from early and term decidua $(n=8)$ and PBMCs of pregnant $(n=9) .{ }^{* \star} p<0.01,{ }^{\star \star \star} p<0.005,{ }^{* \star \star \star} p<$ 0.0001

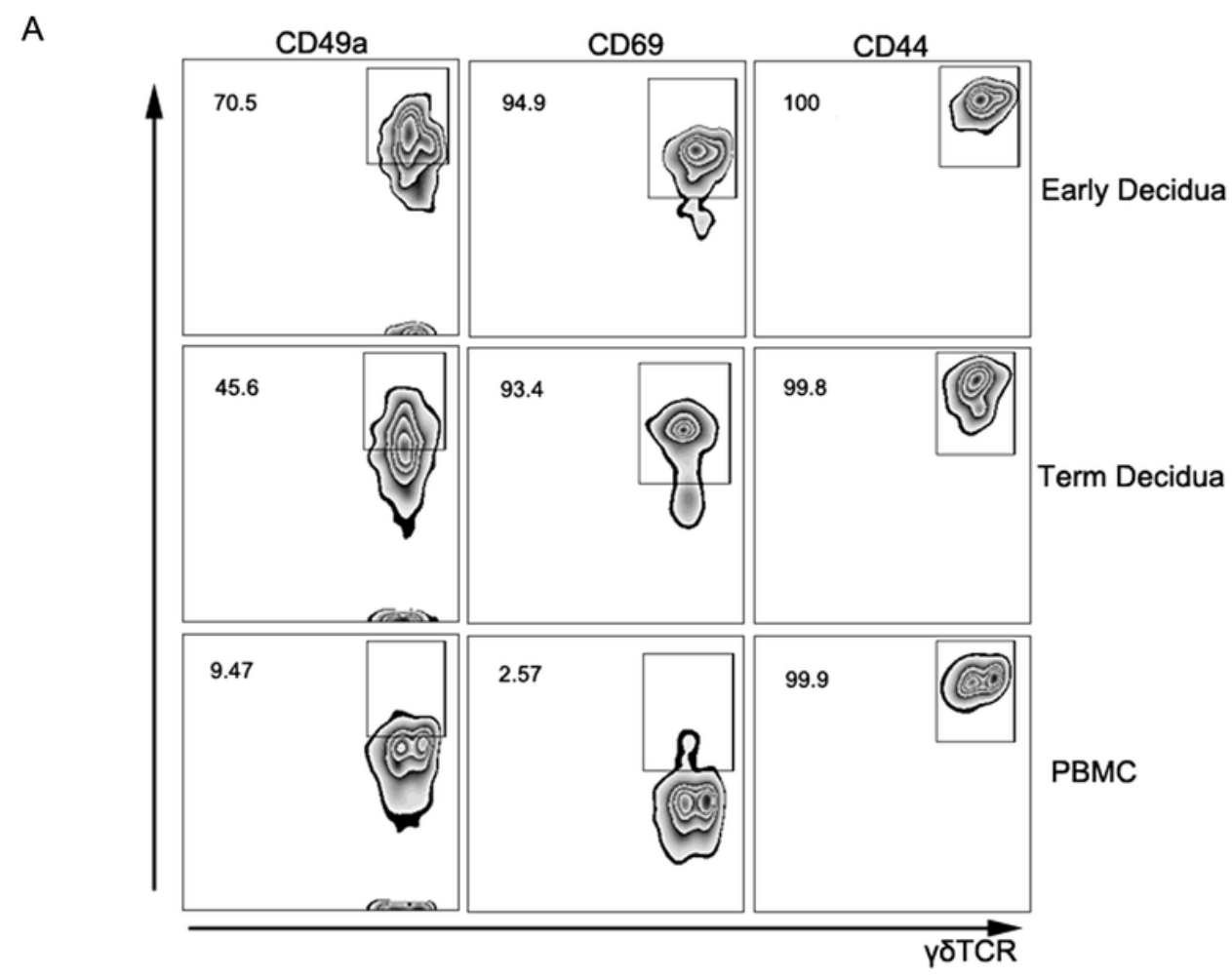

B
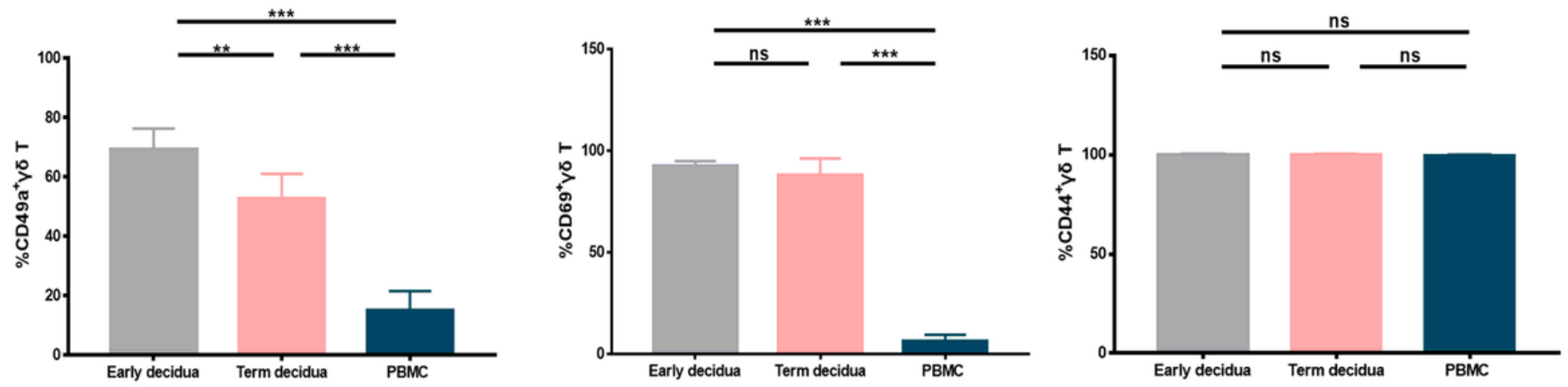

Figure 2 
Identification of tissue-resident maker in human Maternal-fetal interface $\gamma \delta T+$ cells (A) Representative

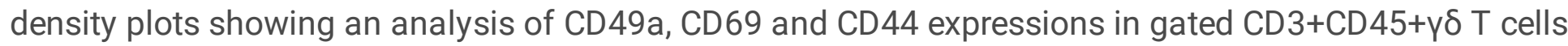
isolated from early, term decidua and PBMCs. (B) Summary data showing percentage of CD49a, CD69

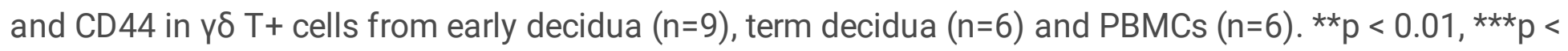
0.005 .

A

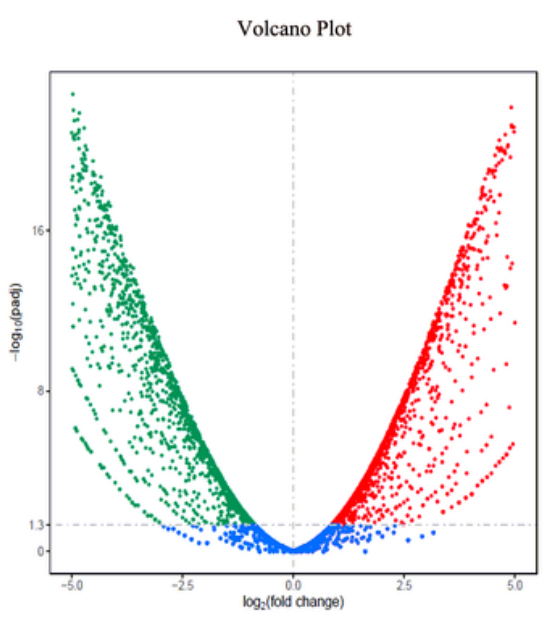

Early decidua VS PBMC

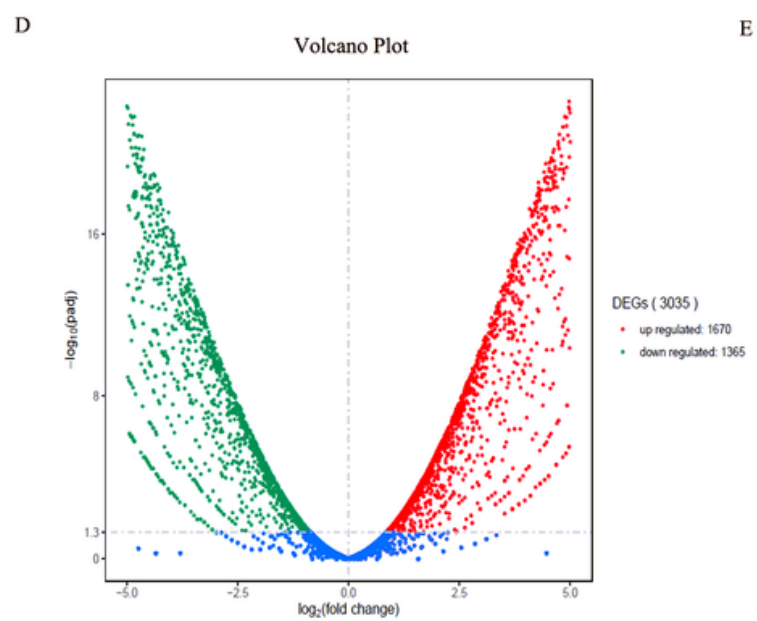

Early decidua VS Term decidua
B

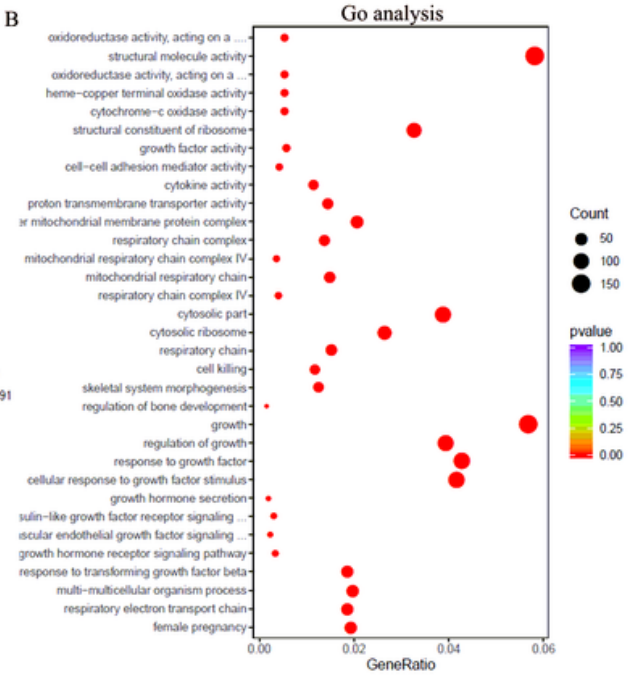

Early decidua VS PBMC

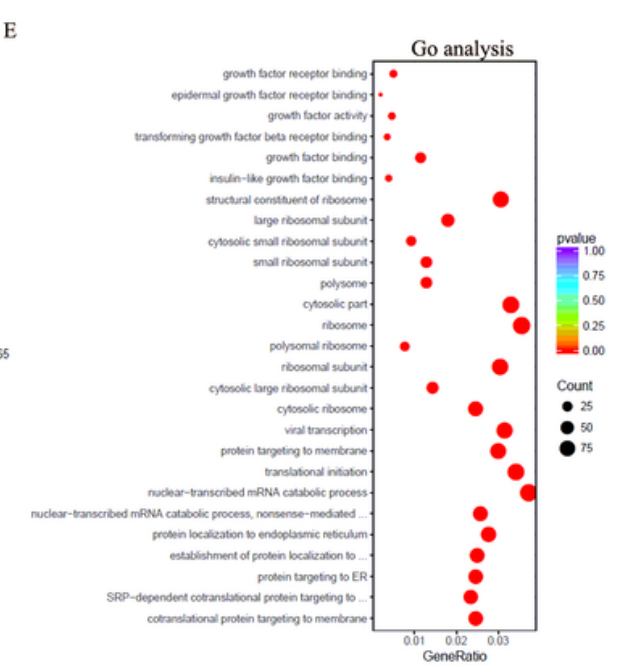

Early decidua VS Term decidua
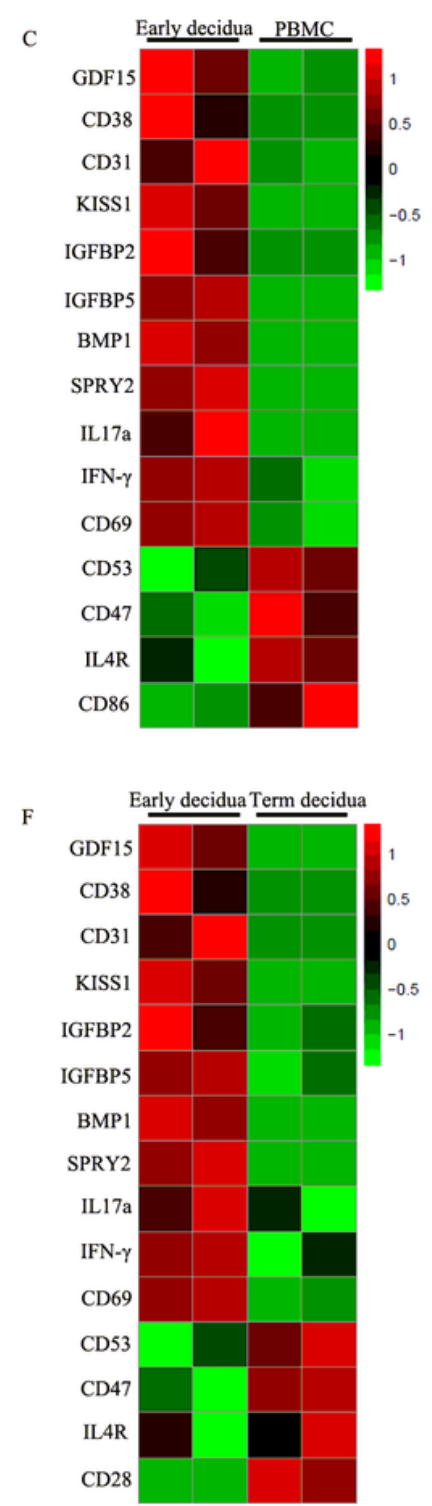

\section{Figure 3}

Gene expression changes in early decidual $\gamma \delta T$ cells. (A) Volcano plot analysis of differential gene expression between early decidual $\gamma \delta T$ cells and PBMCs (log2-fold changes and the corresponding $p$ values for each gene). (B) Go analysis of differentially expressed genes between early decidual $ү \delta T$ and PBMCs. (C) Heatmap showing the different expression of selected genes in early decidual $\gamma \delta \mathrm{T}$ cells and PBMCs. (D) Volcano plot analysis of differential gene expression between early and term decidual $ү \delta T$ cells. (E) Go analysis of differentially expressed genes between early and term decidual $\gamma \delta T$ cells. (F) Heatmap showing the different expression of selected genes in early and term decidual $ү \delta T$ cells. 

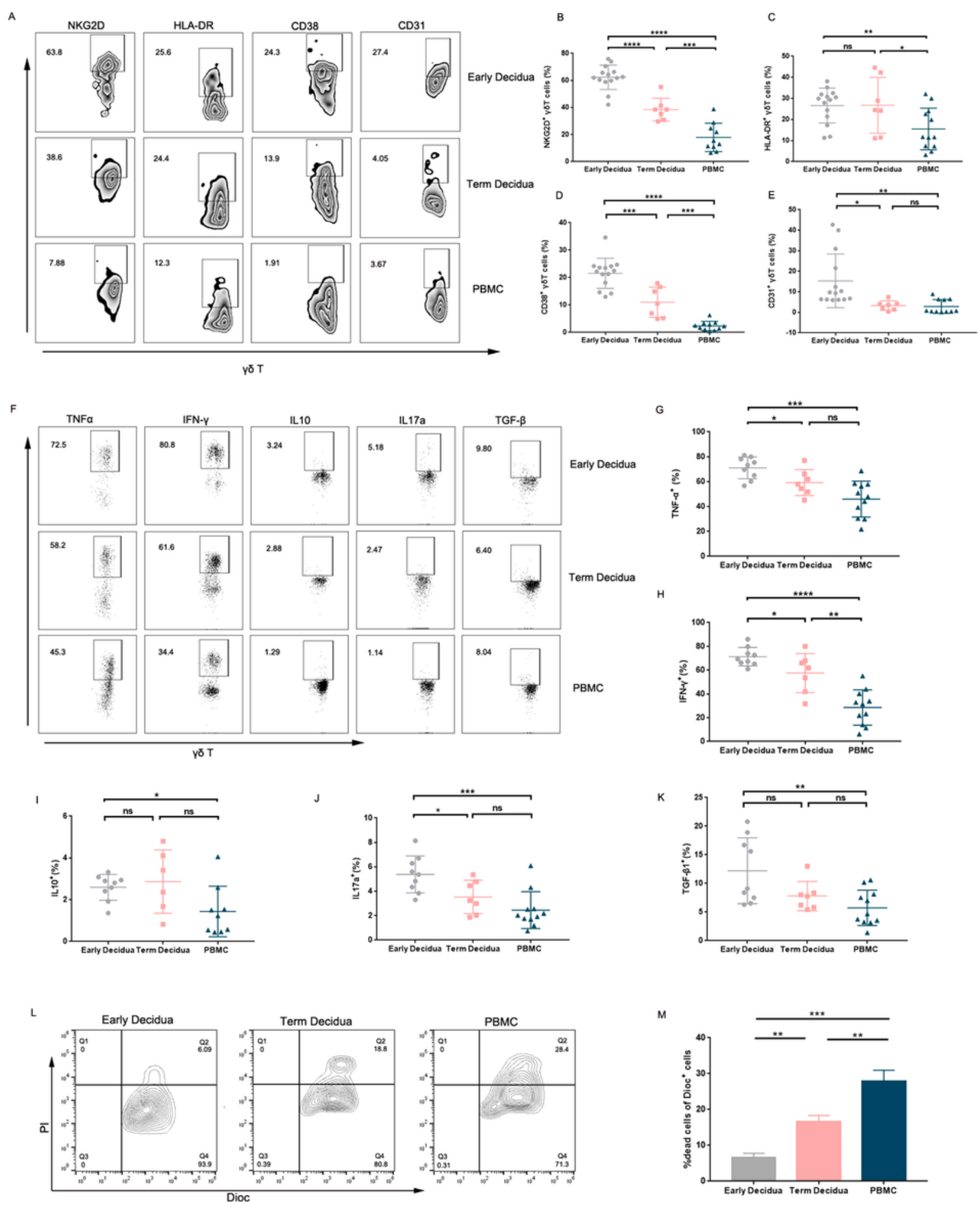

\section{Figure 4}

Higher expression of Activation marker and cytokine in dy $\delta$ T cells from early decidua but shown reduced cytotoxicity. (A) Representative flow cytometry analysis of the expression of NKG2D, HLA-DR, CD38 and CD31 on gated CD3+CD45+ $\gamma \delta T+$ cells in early decidua, term decidua and PBMCs. (B, C, D, E) The percentage of NKG2D, HLA-DR, CD38 and CD31 in in early decidua $(n=14)$, term decidua $(n=7)$ and PBMCs $(n=10)$. (F) Representative flow cytometry analysis of the expression of TNF-a, IFN- $\gamma$, IL10, IL17a 
and TGF- $\beta$ in early decidua, term decidua and PBMCs. (G, H, I, J, K) The frequency of TNF-a, IFN- $\gamma$, IL10, IL17a and TGF- $\beta$ in early decidua $(n=9)$, term decidua $(n=7)$ and PBMCs $(n=11)$. (L) Flow cytometry analysis showed the percentage of Dioc+ PI+ dead A549 cells after gating of Dioc+ cells. The cytotoxicity of $\gamma \delta T$ cells from early, term decidua and PBMCs against A549 cells. Data show a representative experiment in a single individual from each group. (M) Statistical analysis of the cytotoxicity of $\gamma \delta T$ cells in early decidua, term decidua and PBMCs $(n=6) .{ }^{*} p<0.05,{ }^{\star \star} p<0.01,{ }^{\star \star \star} p<0.005,{ }^{\star \star \star *} p<0.0001$.

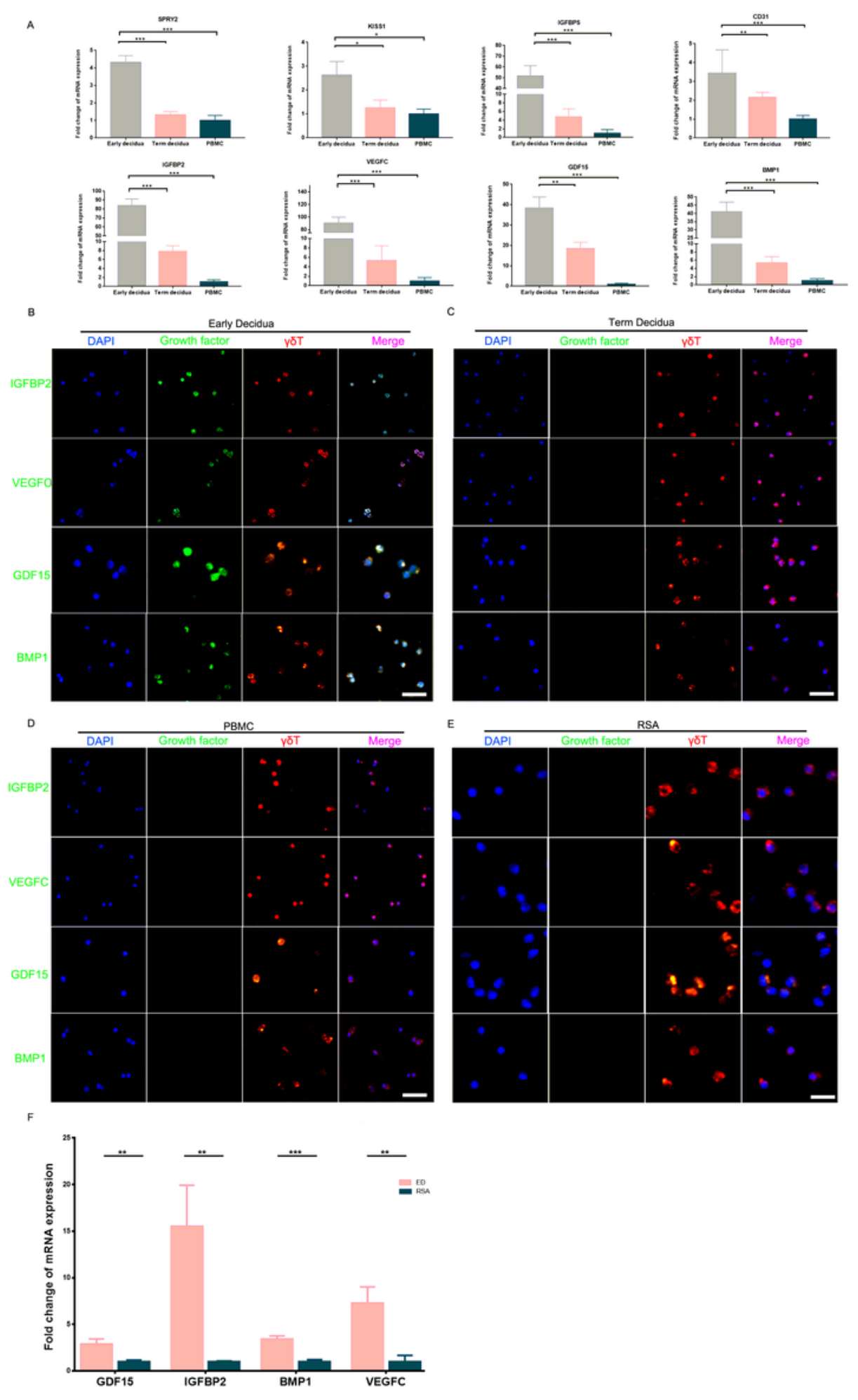

Figure 5 
Identification of Growth factors Secretion in Human $\gamma \delta T+$ Cells. (A) qRT-PCR results of eight selected genes from RNA-sequence. (B) Immunofluorescence of the expressions of Growth factors in sorted $ү \delta T$ cells from early decidua $(n=5)$. (C) Immunofluorescence of the expressions of Growth factors in sorted $y \delta$ T cells from Term decidua ( $n=5$ ). (D) Immunofluorescence of the expressions of Growth factors in sorted y T cells from PBMCs $(n=5)$. (E) Immunofluorescence of the expressions of Growth factors in sorted $y \delta$ T cells from RSA patients $(n=5)$. Scale bar, $50 \mu \mathrm{m}$. (F) qRT-PCR results of Growth factors in sorted $\gamma \delta T$ cells RSA patients $(n=5) .{ }^{*} p<0.05,{ }^{*} p<0.01, * \star \star p<0.005, * \star \star \star p<0.0001$

A

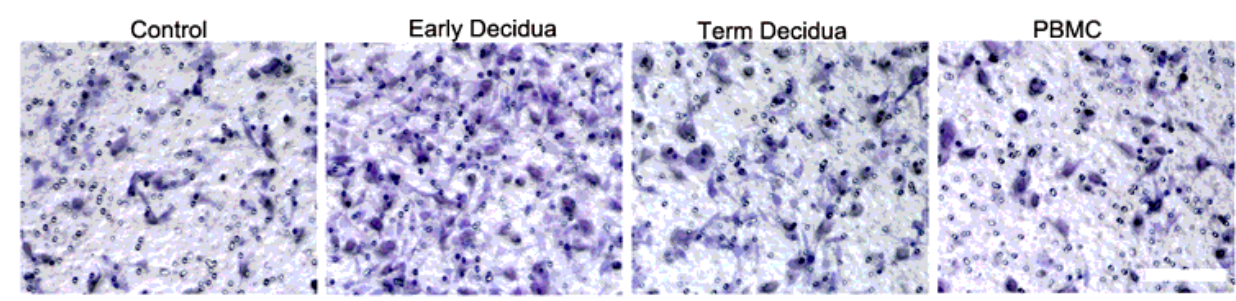

Migration

C

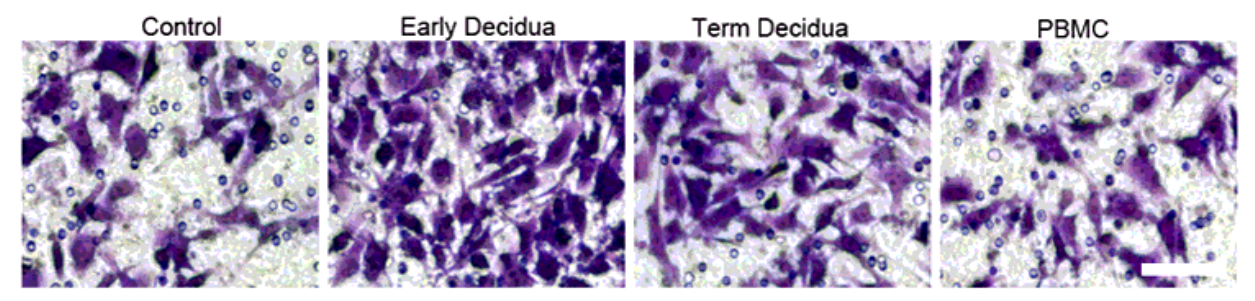

Invasion
B

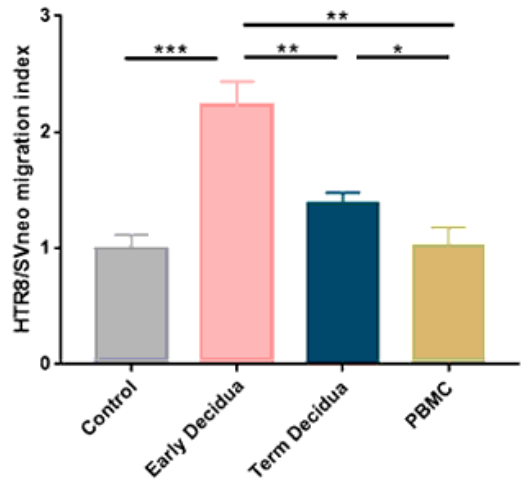

D

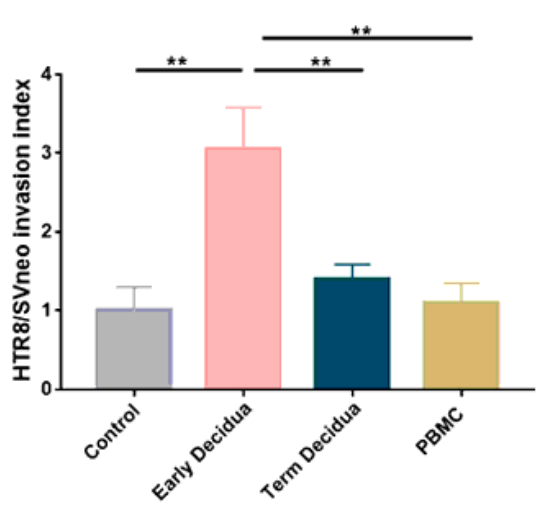

Figure 6

Effect of $\gamma \delta T$ cells on the migration and invasion ability of trophoblasts. (A, C) Transwell assay results showing migrating $(A)$, or invading $(C)$, trophoblasts that reached the lower part of the filter membrane under the indicated conditions (Control/ early decidua / term decidua/ PBMCs: with complete medium/with $\gamma \delta T$ cells from early decidua / with $\gamma \delta T$ cells from term decidua / with $\gamma \delta T$ cells from PBMCs in the lower chamber, respectively), Scale bar, $50 \mu \mathrm{m}$. (B, D) Migration index (B), or Invasion index (D) (number of migrated or invaded cells/the control) $(n=5) .{ }^{*} p<0.05,{ }^{*} p<0.01,{ }^{* \star *} p<0.005$. 
A
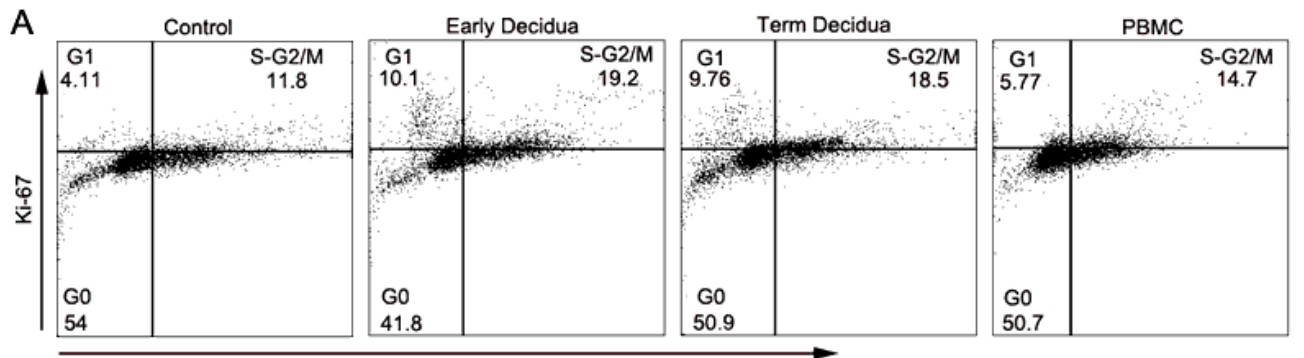

7-AAD

c

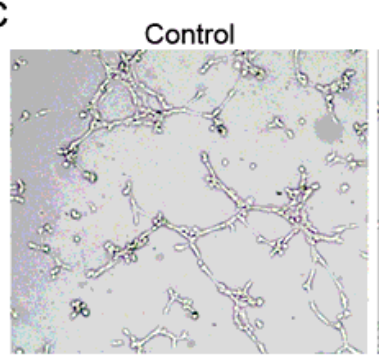

Early Decidua

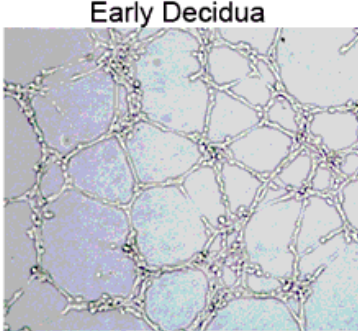

Term Decidua

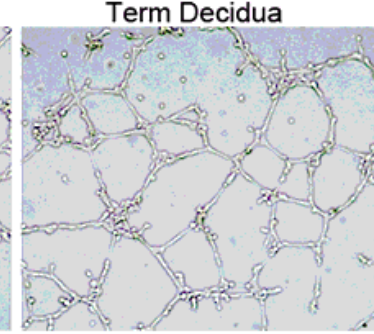

PBMC

B

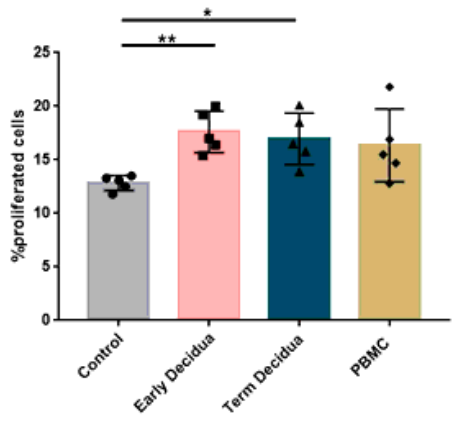

D
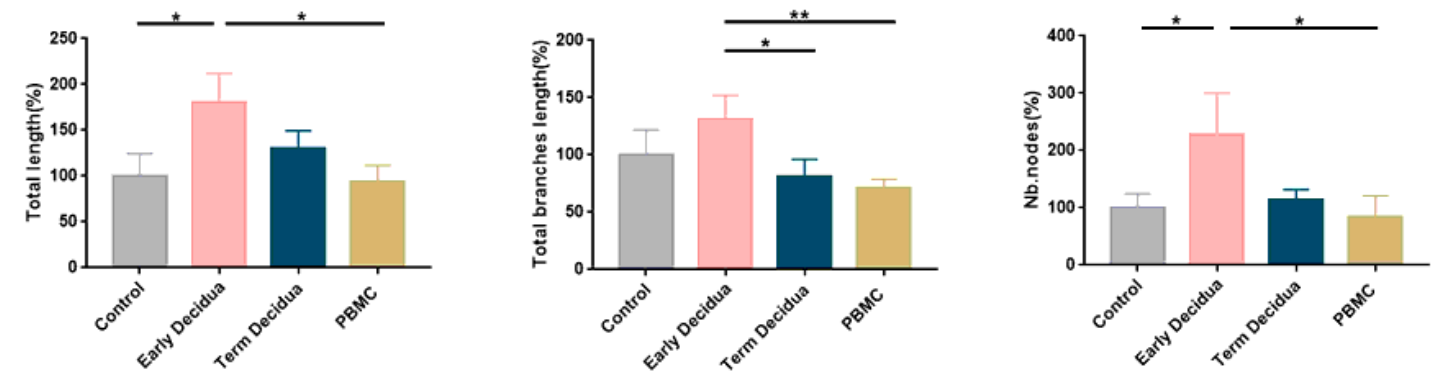

Figure 7

Effect of $\gamma \delta T$ cells on trophoblast proliferation and tube formation. (A) Representative flow cytometry analysis of the expression of trophoblast proliferating cells (S/G2M) in complete medium, and cocultured with $\gamma \delta T$ cells from early decidua, term decidua and PBMCs, respectively. (B) Statistical analysis of proliferating cells in the four different groups $(n=5)$. (C) Network-like structures formed by HTR8/SVneo cells in the condition of complete medium, pre-treated with $\gamma \delta \mathrm{T}$ cells from early decidua, term decidua and PBMCs. Scale bars, $100 \mu \mathrm{m}$. (D) The total length, total branches length, and the number of nodes of HTR8/SVneo cells tube formation were calculated by ImageJ $(n=5) .{ }^{*} p<0.05,{ }^{* \star} p<0.01$. 